\title{
ethic @ \\ DEMOCRACIA E CORPO POLÍTICO EM HOBBES: UMA LEITURA DO ELEMENTS OF LAW
}

\author{
DEMOCRACY AND POLITICAL BODY IN HOBBES: A \\ READING OF THE ELEMENTS OF LAW
}

\author{
DELMO MATTOS DA SILVA ${ }^{1}$ \\ (UFMA/FAPEMA/Brasil)
}

\begin{abstract}
RESUMO
Em Elements of Law, Hobbes evidencia a passagem da multidão ao povo pela qual se evidencia a redução do múltiplo ao uno. A evidência da unidade das vontades assinala ser a democracia o fundamento primeiro, na ordem de constituição das instituições políticas, pelo qual possibilita o aparato consensual e, portanto, a concepção hobbesiana de corpo político. O objetivo desse artigo consiste em compreender os termos da democracia em Hobbes, especificamente no contexto da sua obra Elements of Law e a sua relação com a instauração do corpo político. Trata-se, portanto, de evidenciar o modo pelo qual a ideia de povo opera a conversão das vontades particulares, originalmente em desacordo, em uma vontade única. Na medida em que a união das vontades individuais em direção à submissão da vontade única torna-se a condição para a instauração da democracia. Nesses termos, demonstra-se que a condição de unidade presente no corpo político torna-se compatível com a conciliação das vontades em vistas a um único fim que se identifica com os termos da vontade pública.
\end{abstract}

Palavras-chaves: Multidão; Democracia; Concórdia; Vontade pública; Consenso.

\begin{abstract}
In the Elements of Law, Hobbes evidences the passage from the multitude to the people by which the reduction of the multiple to the one is evidenced. The evidence of the unity of wills indicates that democracy is the first foundation in the order of constitution of political institutions by which it makes possible the consensual apparatus and, therefore, the Hobbesian conception of a political body. The objective of this article is to understand the terms of democracy in Hobbes, specifically in the context of his work Elements of Law and its relation to the establishment of the political body. It is, therefore, to highlight the way in which the idea of the people operates the conversion of particular wills originally in disagreement into a single will. Insofar as the union of individual wills toward the submission of the single will becomes the condition for the establishment of democracy. In these terms, it is demonstrated that the condition of unity present in the political body becomes compatible with the conciliation of wills towards a single end that identifies itself with the terms of the public will.
\end{abstract}

Keywords: Multitude; Democracy; Concord; Public will; Consent. 


\section{Introdução}

A literatura majoritária sobre a reflexão filosófica e política de Hobbes ressalta a sua postura de aproximação aos termos da monarquia e, consequentemente, um distanciamento da democracia. Strauss, por exemplo, em seu livro The Political Philosophy of Hobbes: Its Basis and Its Genesis, assevera que Hobbes defende o regime político por excelência do absolutismo, isto é, a monarquia desfavorecendo qualquer efetividade da democracia. Não obstante, embora Hobbes sustente uma notória convicção de que a monarquia seja a melhor forma de governo, o seu posicionamento não deve se esgotar em uma redução interpretativa de um crítico avesso à democracia como forma de governo.

A despeito dos fortes argumentos que incluem Hobbes desfavorável à democracia, torna-se possível evidenciar que ele assume, segundo Smith (2018), um papel ambíguo em relação às formas de governo, pois a democracia constitui uma parte fundamental do seu projeto filosófico e político. Dessa forma, Hobbes pode ser compreendido como um filósofo que contribui significativamente para a compreensão da democracia e a sua ideia de unidade, mas também é reconhecido como um teórico político que, ao defender a monarquia absolutista, posicionou-se inevitavelmente desfavorável ao regime democrático. ${ }^{2}$

A primeira perspectiva deve ser problematizada com máxima atenção, uma vez que a interpretação de Hobbes como contrário à democracia é largamente consolidada pela literatura tradicional do seu projeto filosófico e político. Diante da segunda perspectiva, fica evidente que considerar a relação de proximidade, e não de repulsa de Hobbes à democracia não deve ser descartada, uma vez que propõe uma distância considerável da interpretação consolidada do filósofo. Nesse aspecto, considera-se indispensável atestar o fato de que os argumentos de Hobbes acerca da democracia não se constituem em renegá-la, mas sim fornecer o argumento fundacional das formas de governo. Essa possibilidade é assinalada, por exemplo, no Elements of Law no qual Hobbes mantém uma correspondência plausível entre a monarquia e a democracia.

Portanto, no cerne da discussão sobre os aspectos da democracia em Hobbes, pelo menos no Elements of Law, devem ser vislumbrados os argumentos do filósofo sobre a passagem da multidão ao povo pela qual se evidencia a redução do múltiplo ao uno. A evidência da unidade das vontades assinala ser a democracia o fundamento primeiro, na ordem de constituição das instituições políticas, pelo qual possibilita o aparato consensual e, portanto, a concepção hobbesiana de corpo político. No Elements of Law, a concepção de povo atesta, sobretudo, a necessidade da 
supressão da multidão para o estabelecimento do corpo político propriamente dito, uma vez que esta não possui uma unidade das vontades, mas sim uma pluralidade de vontades.

Nesse sentido a ideia de povo opera a conversão das vontades particulares, originalmente em desacordo em uma vontade única. Na medida em que a união das vontades individuais em direção à submissão da vontade única torna-se a condição para a instauração da democracia. ${ }^{3}$ De certo, a condição de unidade presente no corpo político torna-se compatível com a conciliação das vontades em vistas a um único fim que, sobretudo, identifica-se com os termos da vontade pública. Por esta razão, Jaume menciona que a incorporação dos indivíduos em um corpo político "simboliza a unificação obtida em retorno pela multidão dos indivíduos, a aparição de um povo na gênese do artificialismo prático" (1985, 40).

O Elements of Law, que representa uma obra anterior à publicação do Leviathan, fora escrita em 1640, mas definitivamente publicada em 1650 na forma de duas obras separadas, a saber, Human Nature e De Corpore Politico, or Elements of Law, Moral and Politic. Em Elements of Law, Hobbes apresenta objetivamente os antecedentes argumentativos que sustentam o seu sistema filosófico e político e culminariam na publicação de $A$ Dialogue between a Philosopher and a Student of Common Laws of England. No que concerne à democracia, no referido trabalho, Hobbes demonstra declaradamente uma postura diferenciada a respeito do tema, na medida em que assinala ser a democracia o fundamento das demais formas de governo.

A motivação de Hobbes no Elements of Law em relação à democracia consiste em evidenciar o papel do consenso pelo qual se estabelecem as formas de governo que pressupõem a democracia como fundamento. Essa possibilidade evidencia a preocupação de Hobbes com a instituição do corpo político baseado numa confluência de vontades que culminam na união da multidão, ou seja, por um processo puramente artificial. Desse modo, a democracia fornece os elementos necessários para a instauração da monarquia, mediante um consenso no qual a vontade de todos seja representada pela vontade de um único homem. Conforme observa Tuck, em seu projeto filosófico e político, Hobbes possui um considerável interesse pela democracia, "embora possa (em certa medida) ser orientado pelo desejo de defender uma monarquia idealizada" $(2006,114)$.

$\mathrm{Na}$ verdade, Hobbes baseou-se em todas as outras formas de governo, inclusive a monarquia com as mesmas determinações da democracia, assinalando uma profunda preferência pela legitimidade do povo soberano. Nesse momento, cabe uma indagação: será que Hobbes, nas suas obras iniciais, por exemplo Elements of Law, enfatizava realmente 
as suas preferências democráticas em detrimento à sua opção monarquista? Ou, Hobbes, por uma questão objetiva, omitiu suas preferências democráticas evidenciando uma posição absolutamente monárquica?

Portanto, no Elements of Law, a perspectiva de Hobbes perante o governo democrático não é tão pessimista quanto ao Leviathan, e isso se deve, sobretudo, por ele considerar ser a democracia um elemento de transição, tanto para a aristocracia quanto para a monarquia. Embora não se deva atribuir nenhuma intenção propriamente democrática em Hobbes, pelo menos em Elements of Law, no seu projeto de constituição política, especificamente, em sua defesa pela monarquia, os elementos da democracia tornam-se fundamentais. Desse modo, a forma de governo democrático presente no Elements of Law representa uma considerável relevância a ponto de descaracterizar as indicações de que Hobbes é um filósofo contrário às determinações da democracia. Sendo assim, quando se expõe a questão da relação de Hobbes com a monarquia absolutista tornase necessário, portanto, requerer os termos da democracia como um elemento imprescindível na consecução do seu projeto político e filosófico.

Diante dessas considerações, o objetivo do presente artigo consiste em compreender os termos da democracia em Hobbes, especificamente no contexto da sua obra Elements of Law e a sua relação com a instauração do corpo político. ${ }^{4}$ Diante desse propósito, a hipótese pretendida diz respeito a evidenciar a configuração da democracia baseada na tensão argumentativa de Hobbes entre multidão e povo. Através dessa tensão argumentativa põem-se em discussão os pressupostos da unidade pela qual se configura a noção de povo e corpo político. ${ }^{5}$

Sendo assim, propõe-se fundamentalmente compreender a relação paradoxal de Hobbes com os termos da democracia, o que se constitui uma tarefa de extrema relevância para evidenciar como o filósofo constrói a sua teoria da representação no Leviathan, culminando no argumento da legitimidade e autorização do poder soberano. Nesses termos, a estrutura do corpo político, no Elements of Law, diz que se deve fornecer uma vontade única à multidão pelo que se configura a noção de povo. Em vista disso, torna-se necessário evidenciar que o processo de redução de uma pluralidade de vontades a uma única vontade é conduzido pelo processo de convenção no qual o acordo de vontades torna-se necessariamente a vontade de todos.

Para tanto, em um primeiro momento, discute-se o processo de constituição da vontade única pela qual se dissipa a multidão. Trata-se, portanto, de evidenciar o processo de condução de uma vontade única pela qual se configura o corpo político pela unidade das vontades particulares. 
Em um segundo momento, examina-se a relação entre união e consenso como elemento primordial para a compreensão da formação do corpo político, uma vez que demonstra a necessidade de uma conformidade de vontades. Trata-se, portanto, de discutir a unidade representativa das vontades pela transformação da multiplicidade natural das vontades em uma unidade artificial e ordenada.

Por fim, no último momento, examina-se a construção da democracia através do estabelecimento do corpo político como um elemento artificial capaz de engendrar uma pessoa civil. Diante disso, demonstra-se a instauração da democracia baseada no argumento da preservação da unidade enquanto povo, uma vez que se institui uma vontade única e soberana. Para tanto, evidencia-se que as ações particulares típicas de uma multidão desorganizada e discordante se desfaz em razão de uma ação única de uma vontade única capaz de engendrar a figura do soberano.

\section{Multidão e vontade singular}

No Elements of Law, Hobbes evidencia que, no processo deliberativo, a vontade corresponde ao último apetite ou ao último medo. Nesse sentido, o processo deliberativo determina as condições de liberdade de ação, pois entre a alternância do medo e do apetite origina-se a indecisão de realizar ou não uma determinada ação. Com efeito, esse espaço de indecisão condiciona a possibilidade de escolhas para realizar ou não uma determinada ação, o que, de certa forma, resulta no fim do processo deliberativo. Dessa forma fica, portanto, evidente que o fim do processo deliberativo consiste em por fim à liberdade de praticar ou evitar uma determinada ação. ${ }^{6}$

Não obstante, se toda a ação depende da inclinação, pois das inclinações provém a vontade, deve-se, da mesma forma, compreender que todas as ações e omissões consideradas voluntárias procedem da vontade. Assim, enquanto a série deliberativa condicionante encontra-se entre fazer ou não uma ação, a vontade engendra a condição de finalizar a liberdade. Exatamente nessa perspectiva que Hobbes determina a vontade como um ato voluntário (HOBBES, 2010). Além disso, na condição de um ato voluntário, a vontade manifesta uma aptidão para medir as consequências das ações futuras de cessar o processo deliberativo. ${ }^{7}$

Considerando tal perspectiva, as ações e omissões consideradas voluntárias procedem indubitavelmente da vontade caracterizada, por conseguinte, pelo alto grau de autonomia no que concerne às escolhas de omitir ou fazer algo. Em Elements of Law fica evidente que tanto o medo quanto o desejo são fatores causais da vontade, na medida que envolvem 
uma expectativa a respeito do nosso poder de realizar o que é requerido pela inclinação. Nesse caso, segundo Hobbes (2010), no âmbito da deliberação existem duas condições para que a ação seja deliberada, ou seja, a ação futura e a esperança de realizá-la ou a possibilidade de não realizá-la, "pois o apetite e o medo são expectativas do futuro; e não há expectativa de bem sem esperança" (HOBBES, 2010, 59).

$O$ processo de determinação da vontade engendra a capacidade de imaginar o futuro com base no passado que, por sua vez, determina uma cadeia de desejos e aversões sobre um determinado objeto, prevalecendo a indeterminação de um sentimento sobre os demais. Trata-se, portanto, da expressão da vontade singular de cada homem que, determinadas por inclinações dissociadas, produzem ações que reciprocamente se anulam, mas se a multidão ao contratar entre si, no sentido da vontade de um homem ou do acordo das vontades da maioria dos seus membros, será caracterizada como vontade de muitos. Logo, diante dos argumentos do Elements of Law torna-se possível pressupor que a multidão não se caracteriza como de uma, mas de muitas vontades sem coerência e completamente desorganizada. ${ }^{8}$

Em todo caso, a dissociação das vontades particulares acarreta a oposição ou a luta entre os homens, deflagrando a impossibilidade de vínculos de união entre as vontades singulares. Na verdade, o efeito recíproco de anulações de ações no âmbito da multidão não confere uma naturalidade à vontade, uma vez que se constata a ausência efetiva de elementos que possam conformá-la a um mesmo e único fim. Desse modo, na perspectiva de Hobbes, no Elements of Law não há sentido em pressupor uma vontade coletiva quando as vontades particulares dependem das circunstâncias que determinam um bem para si mesmo e, consequentemente, não um bem para o outro. Segundo Leivas:

Um enxame de abelhas é tão somente um grupamento de vontades naturais que competem entre si no sentido do bem comum, mas são incapazes de constituírem vontade volitiva (LEIVAS, 2019, 257).

Para formar o corpo político, Hobbes menciona no Elements of Law que deve-se fornecer uma vontade única à multidão. Para tanto, torna-se necessário desfazer a desorganização de uma multidão desunida em prol da constituição da vontade de um povo. O processo de redução de uma pluralidade de vontades a uma única vontade é conduzido pelo processo de convenção no qual o acordo de vontades torna-se necessariamente a vontade de todos. Assim, a vontade de todos torna-se uma pessoa capaz de representar a vontade de muitos numa só vontade, na medida que a 
multidão na forma natural não pode ser considerada uma, mas muitos. Segundo Souki:

Assim, a ação dos homens dentro da multidão, mesmo se ela pode aparecer como única a um observador superficial que atribuiria à multidão a corência que ela não tem, é, na verdade, fragmentação e dispersão (SOUKI, 2008, 210).

Na perspectiva de Hobbes, a multidão, embora constituída por uma só pessoa é incapaz de determinar uma ação propriamente dita, na medida que a "multidão de pessoas reunidas" nem sempre coincide em seus desígnios (HOBBES, 2010, 106). ${ }^{9}$ Nesse sentido, não se deve prever uma ordem na multidão, afinal a ordem, segundo Hobbes, é consequência direta da manifestação de vontade orientada em um só sentido. Por este motivo, Hobbes deixa claro no Elements of Law que a multidão não é apta a configurar de forma natural uma unidade, pois o que prevalece entre os homens são a sua própria vontade e o seu juízo peculiar acerca de todas as coisas que podem ter propostas. Trata-se, portanto de uma configuração na qual cada um possui o direito de todas as coisas, segundo o qual, nas palavras de Hobbes "não há lugar para o meum e Teumm [meu e o teu] entre eles" (HOBBES, 2010, 106). Desse modo, mesmo que sejam previstas ações dos homens no interior da multidão com aparência de uma única ação, trata-se de uma falsa aparência, pois o que se constata é uma incoerência tamanha, a ponto de ressaltar a sua fragmentação e dispersão natural. ${ }^{10}$

No Elements of Law qualquer forma de condução de um estabelecimento de um estado de paz deve ser compreendido por intermédio da unidade. Segundo Hobbes (2010), a redução das diversas vontades a uma só equipara-se a uma unidade de vontades dirigidas para um mesmo objetivo, pelo qual as vontades particulares aceitam ser submetidas a uma única vontade. Não obstante, o processo de constituição de uma vontade única possui suas razões na comparação da natureza belicosa dos homens no âmbito do estado de natureza. Diante dessa constatação, Hobbes, no Elements of Law afirma que a ênfase em tal comparação determina a pressuposição de que a multidão não garante a proteção e defesa suficiente quando se apresentam divergências de opinião em decorrência de interessses puramente particulares. ${ }^{11}$

Nesse âmbito, as vontades individuais se dissipam pela ocorrência desenfreada de aquisição de poder que, das condições naturais, inevitavelmente resultam numa guerra de vontades. Conforme explicita Smith, "a guerra das vontades numa total ausência de um poder 
suficientemente capaz de conformar as vontades particulares demonstra efetivamente uma disjunção das vontades" (2018, 148). Torna-se necessário, portanto, um elemento que unifique as vontades para que seja efetivada uma unidade ou o consenso. Assim, diferentemente do Leviathan, no Elements of Law a inserção do argumento da unidade da pluralidade das vontades enseja a configuração do que Hobbes denomina de povo. Notase, portanto, que a configuração de povo, diferentemente da multidão, contém uma vontade única pela qual se supera a multiplicidade de vontades através de um processo de implementação da unidade e, sobretudo, pelo direcionamento das ações a um único objetivo. ${ }^{12}$

As considerações acerca da multidão no Elements of Law sinaliza para o argumento de Hobbes segundo o qual se não houver outro modo de unir, tanto os recursos, quanto as forças naturais para resistir a tais inimigos, a paz seria completamente vã. Desse modo, pela leitura do Elements of Law são estabelecidas as razões pelas quais se institui um corpo político quando um homem sujeita a sua vontade ao poder dos outros, o qual se pretende obter segurança.

\section{Instituição da unidade política}

Retornando às determinações da unidade das vontades no Elements of Law, Hobbes menciona que quando várias vontades concorrem para uma única ação ou efeito, denomina-se consenso. Trata-se, portanto, de uma "única vontade de muitos homens" que objetivam não mais efeitos diversos e incompatíveis, mas o mesmo e único efeito direcionado para um fim comum e no qual a vontade de um único homem representa a vontade de todos (HOBBES, 2010, 107). Na perspectiva de instauração de uma vontade única, apresenta irremediavelmente o rompimento das particularidades das ações múltiplas pelas quais se assegura o engendramento das condições de transferência da multidão à unidade ao corpo político, ou seja, "uma multidão de homens reunidos em uma só pessoa, por meio de um poder comum, para a paz, defesa e benefício comum" (HOBBES, 2010, 100).

No Elements of Law, o consenso ou a concórdia resguarda em si a reorientação das vontades nas quais culmina o que Hobbes denomina, assim como no De cive e no Leviathan, como união. A relação entre união e consenso é primordial para a compreensão da formação do corpo político, uma vez que demonstra a necessidade de uma conformidade de vontades, ainda que não mencione a ideia de representação típica do Leviathan.

No âmago da concepção do consenso ou da concórdia, Hobbes questiona o modo pelo qual a concórdia possibilita um prolongamento de sinais que possam efetivar uma ajuda mútua contra um inimigo comum. 
Segundo Jakonen,

Hobbes ressalta que não há possibilidade do consenso ou concórdia em oferecer segurança suficiente para instaurar a paz. Desse modo, a concórdia é artificialmente construída, uma vez que não se concebe por obra de Deus, mas um efeito das vontades $(2013,200)$.

Não obstante, a realização da união confere à concórdia um significado muito próximo à primeira na medida que constituem a instauração de um acordo artificial pelo qual cada homem se obriga a um único homem ou conselho.

No Elements of Law, consenso difere da união se somente puder trazer algum benefício, insiste o filósofo, se houver a presença de um poder comum que conforme as vontades. Sendo assim, a conformidade das vontades proveniente da união permite a unidade requerida pelas particularidades discordantes, de modo que aquelas ações múltiplas, próprias da multidão causem uma artificialidade denominada de povo. Segundo Hobbes, confundir o movimento de uma multidão com a ação própria do povo é realizar um contrassenso, pois o povo constitui-se baseado na sua unidade inerente e, por assim, constituído por uma só vontade pela qual atribui-se uma ação. ${ }^{13}$

Com isso, fica bastante claro que, no Elements of Law, a multidão baseada na soma de particularidades não possibilita a coerência extraída das particularidades, uma vez que é própria daqueles que direcionam suas respectivas vontades a um fim. Além disso, no âmbito da multidão, o que se concebe é uma quantidade de ações e desejos equivalentes ao número de homens, mas à aparência de uma ação comum. Na perspectiva de Hoekstra,

ignorar a diferença entre povo e multidão predispõe à sedição. Em outras palavras, funda-se um grande perigo para o governo civil, especialmente o monárquico, que não se distinga entre o que é um povo e o que é uma multidão (2006, 34).

Não se pode deixar de assinalar que no Elements of Law, esta unanimidade é construída pelo consentimento individual, ainda que Hobbes indique uma ênfase à unidade das vontades da multidão. Assim, o ato de instituição do corpo político não é um ato da vontade coletiva dos homens, mas, sobretudo, de cada um dos homens em particular, seus respectivos sinais de vontade. É a unidade representativa das vontades que transforma 
a multiplicidade natural das vontades em uma unidade artificial e ordenada. De acordo com Jakonen, "é essa mesma unidade que converte a multidão em povo e dá início à vida civil" $(2013,2002)$. Em outras palavras podemos afirmar que, embora o corpo político se institua através da multidão, tal instituição não se institui pela multiplicidade de vontade, mas pela convergência das vontades. ${ }^{14}$

Diante de tais apontamentos fica, portanto, evidente os principais elementos pelos quais podem ser compreendidas a forma na qual Hobbes constitui o corpo político e, sobretudo, as funções atribuídas ao povo e ao soberano. O tratamento fornecido ao povo satisfaz plenamente ao que o filósofo compreende por pessoa civil, ou seja, um homem ou uma assembleia de homens cuja vontade contém a vontade de cada homem em particular. Nesse caso, acrescenta Hobbes, as vontades dos seus membros estão virtualmente compreendidas no soberano. Como consequência, aquele que possui o poder soberano realizará tudo o que for exigido e reivindicado "sob o nome de seu o que antes denominava de deles" (HOBBES, 2010, 97). Desse modo, a vontade do soberano não deve ser considerada uma vontade que substitui e se impõe à vontade da multidão unida numa só vontade, mas ao contrário, coincide com ela.

Segundo Hobbes em Elements of Law, em qualquer governo é o povo quem governa. Até mesmo nas monarquias é o povo quem detém o direito de mando, uma vez que, o povo diz sua vontade através da vontade de um homem, ao passo que a multidão é o mesmo que os cidadãos, isto é, que os súditos. Esta relação demarca perfeitamente aquilo que a lei suprema determina, isto é, Salus Populi (a defesa do povo) que, na verdade, significa na obediência e na unidade por meio da qual pretende-se evitar o estado de beligerância. Não obstante, Hobbes é bastante claro no que concerne ao benefício pelo qual o corpo político é instituído, ou seja, a paz e a preservação entre os homens não se constituindo qualquer outro benefício.

A consequência desse posicionamento de Hobbes no Elements of Law é a construção da redução da vontade particular a uma vontade soberana que, sobretudo, reafirma a ausência da dissonância das vontades. Trata-se de uma convergência de vontades instaurada pela transposição da particularidade em uma vontade pública. Esta caracterização permite Hobbes sustentar o argumento da substituição das vontades particulares pela vontade de um único homem ou conselho sem a necessidade de uma transferência legítima de direitos. Essa perspectiva é o que torna Elements of Law uma obra paradigmática no contexto do sistema filosófico e político de Hobbes.

Certamente, como observa Zarka (2001), a transferência de direitos requerida pela contraposição entre multidão e povo, ou melhor, entre 
diversidade e unidade. Esse jogo do múltiplo e da unidade é o que torna a vontade do soberano pública. A emergência de uma vontade pública, que é, portanto, a vontade do povo que repousa na determinação de uma união de vontade capaz de subsumir a vontade de todos pela vontade do soberano. De certa forma, a vontade pública está irremediavelmente associada a uma redução de vontades particulares dirigidas para um fim comum.

Nesse mesmo sentido que é estabelecida a transformação da multidão desorganizada em um poder soberano, isto é, um sujeito político engendrado pelo confronto entre o natural e o artificial, entre o uno e o múltiplo. Na tentativa de tornar menos abstrato o conceito vontade pública, Zarka (2001) afirma, com base na dicotomia multidão e povo, que o reconhecimento da vontade política como unidade das vontades ratifica a convenção das vontades através da substituição da multiplicidade pela unidade.

$\mathrm{Na}$ verdade, considerações realizadas por Zarka (2001) a respeito do conteúdo vontade pública fornecem suporte a um conceito substancial de vontade geral, isto é, a vontade geral pode assim ser definida como a vontade do corpo político, que visa a instituição do poder soberano, o qual é instituído pela vontade particular e busca conformar os interesses individuais ao interesse comum, preservando, sobretudo, aquela condição imprescindível para a constituição daquele poder comum necessário à instauração da vontade pública soberana.

Decerto, o processo de configuração do consenso entre os homens instaura uma unanimidade com relação à fundação da representação. Diante disso, a soberania torna-se um produto da vontade de todos os homens que adentram a relação forjada pela dinâmica da autopreservação. Não obstante, esta unanimidade é construída pelo consentimento singular, não pelo consenso da multidão. Logo, o ato de instituição da representação não é um ato da vontade coletiva dos homens, mas de cada um dos homens tomados individualmente.

\section{Unidade e democracia}

É reconhecido o recurso demonstrativo utilizado por Hobbes para estabelecer a distinção entre o que é artificial e o que é natural na sua explicação do modo como o poder soberano pode ser adquirido ou conforme o Elements of Law: "formas de erigir o corpo político" (HOBBES, 2010, 105). Essa determinação conduziu Strauss a empreender uma discussão sobre a relação entre monarquia e democracia, ou melhor, entre medo e esperança. 
Trata-se, portanto, daquela distinção entre o corpo político instituído de forma arbitrária, ou seja, por aquisição, e aquele gerado por meio do engenho humano pelos homens a partir do consenso de uma multidão, a saber, por instituição. Assim, enquanto o Estado por aquisição é instituído "por força natural", isto é, aquele em que o poder soberano é adquirido por imposição, o Estado por instituição, por sua vez, é aquele em que cada homem concorda voluntariamente entre si, portanto, de forma artificial.

Em Elements of Law, Hobbes assinala uma ausência de contradição entre a monarquia e a democracia. Essa pretensa equivalência evidencia uma origem natural, enquanto a democracia, artificial. Desse modo, o caráter monárquico do Estado natural, isto é, do Estado por aquisição, constitui a forma governamental mais elementar. Essa posição de Hobbes baseia-se sobretudo na distinção, seguindo Strauss, entre os dois modos de entender o Estado natural, ou seja, que pode ser compreendido por ser um estado despótico baseado na conquista e, por outro lado, a monarquia patrimonial baseada na autoridade paterna. Sendo assim, Hobbes, em Elements of Law trata a monarquia com caráter patrimonial e não despótico.

Com isso, observa Strauss: "(...) para Hobbes, a monarquia e o reino patrimonial são originalmente idênticos" $(2016,110)$. Não obstante, na distinção entre Estado artificial e Estado natural Hobbes insere a democracia, a aristocracia e a monarquia como Estado artificial, o que difere, por conseguinte, da monarquia patrimonial e a monarquia. Desse modo, Hobbes estabelece que o Estado artificial é democrático e o Estado natural constitui a monarquia patrimonial.

Segundo Strauss

Seria erro acreditar que Hobbes preferia originalmente a monarquia, em razão da sua origem natural, à democracia artificial. Acontece que a primeira exposição sistemática das suas opiniões é a mais democrática. Que a precedência da democracia sobre as outras formas artificiais de Estado é algo afirmado de modo deveras decisivo nos Elementos (...). Os fatos que seguem são menos equívocos. Nos Elementos, a afirmação de Aristóteles que o objeto da democracia é a liberdade encontra um tratamento mais justo da parte de Hobbes, apesar de sua sujeição a essa opinião aristotélica, do que escritos posteriores. Além disso, encontra-se nos Elementos uma observação sobre o Estado artificial que parece o resíduo de um argumento em favor da democracia e que ocorre de novo nas apresentações posteriores apenas sob uma forma bastante enfraquecida $(2016,111)$. 
Não obstante, Hobbes em Elements of Law assinala que o motivo principal que conduz ao Estado natural é o medo e, por outro lado, o motivo da instauração do Estado artificial é a esperança. Há uma oposição entre o Estado natural e o artificial. Essa antítese, segundo Strauss, deixa transparecer que Hobbes privilegia a democracia em detrimento da monarquia, uma vez que a democracia é a forma primária do Estado artificial. Nas palavras de Hobbes:

(...) é provável desde o princípio que Hobbes estivesse aberto para ideias democráticas no período humanista, muito mais do que estaria depois. Nos anos de maturidade, ele sempre apontou os autores clássicos como a causa principal das ideias democráticas da sua época (HOBBES, 2010, 122).

Se a democracia se baseia na esperança, conforme Hobbes enfatiza quando distingue Estado natural do Estado artificial, deve consequentemente aproximar-se da perspectiva da democracia pelo seu viés da esperança. No entanto, a monarquia patrimonial distingue-se da monarquia propriamente dita pelo seu apelo à paixão do medo. $\mathrm{Na}$ perspectiva da esperança, a democracia resguarda seu interesse, segundo Strauss pela representação da artificialidade presente na instituição da soberania do estado. O caráter artificial da democracia assinala o estabelecimento do corpo político como um elemento artificial capaz de engendrar uma pessoa civil.

Uma democracia é, portanto, segundo Hobbes (2010) uma espécie de governo em que o soberano-representante é o próprio povo reunido em assembleia de todos, no qual cada homem particular é considerado um súdito. Nesse sentido, a instauração da democracia corrobora a preservação da unidade enquanto povo, uma vez que se institui uma vontade única e soberana. Não há mais ações particulares típicas de uma multidão desorganizada e discordante, mas uma ação única de uma vontade única. Dessa forma, a democracia se reserva numa instrutura na qual o povo se constitui como unidade que transcende às particularidades numa coerência que determina a soberania. Segundo Hobbes (2010), independente da forma de governo, o povo é quem governa quando expressa a sua vontade através de uma vontade representativa. ${ }^{15}$

Desse modo, Hobbes evidencia uma relação próxima entre soberano e povo de modo que as ações de ambos se assemelham. Essa semelhança denota que as ações do soberano se configuram a essência do corpo político. No entanto, deve ficar claro que não há, no ato da construção da democracia, nenhum acordo a ser realizado entre o soberano e qualquer 
súdito em particular na condição de multidão. A democracia, menciona Hobbes, é constituída por pactos particulares por cada homem, ou seja, trata-se de acordos constituídos por cada homem em benefício da sua própria defesa e a obtenção da paz. Nesse processo, portanto, funda-se a obediência pela qual a maioria detém a unanimidade de reunião em vista a deliberar sobre algo comum. Segundo Hobbes: "E é isso que dá existência à democracia; os gregos chamavam a assembleia soberana pelo nome de Demus (id est, o povo) de onde vem o termo democracia" $(2010,116)$.

Nesse sentido, Hobbes assinala que, em todas as democracias, o direito de soberania esteja na assembleia que, correspondente ao corpo inteiro, sempre recairá em um homem singular ou em um pequeno número de homens o uso desse direito. Trata-se, portanto dos termos da representatividade pela qual Hobbes explicita a determinação de que a vontade de um único homem implique a vontade de todos. Tal união que se configura como um corpo político pelo qual a vontade da maioria, representada numa única vontade, constitui propriamente a democracia, que, por sua vez, configura-se, portanto, em um processo de unidade das vontades que na sua confluência forma a figura do soberano que, imbuído no seu direito legítimo de representar as vontades particulares, age em nome daqueles que decidiram a sua representatividade.

Em outros termos, o ato que institui a soberania na qual a diversidade das vontades adquire consistência e unidade coincide formalmente com a constituição do caráter absoluto do poder soberano, à medida que confere o reconhecimento da legitimidade de que a vontade de cada homem é incondicionalmente a vontade soberana. Uma vez posto que a concordância das vontades estabelece uma unidade às ações, torna-se necessário determinar como essas são efetivamente representadas pela figura teórica da pessoa fictícia.

Não obstante, no âmbito da concepção de Hobbes de democracia, as deliberações públicas são realizadas por ocasião de reuniões ou assembleias nas quais comparece grande número de pessoas. Assim, no governo popular, evidencia Copp (1989), o portador da pessoa pública é capaz de reduzir as diversas vontades presentes na multidão a uma única vontade expressa na pessoa representante do poder soberano. Por esta razão, aquele que se diz portador de tal pessoa, seja este um homem ou uma assembleia de homens, é denominado por Hobbes de soberano, a quem pertence o poder soberano. De outro modo, todos aqueles destituídos de tal poder soberano, são denominados de súditos ou cidadãos. Sendo, portanto, as ações praticadas pelo poder soberano ações, também, daqueles que consentiram que fossem praticadas, temos que aceitar a 
premissa de que o soberano ao agir não age contra a vontade daqueles que Ihe consentiram o ato.

\section{Conclusão}

Certamente foi Hobbes quem enfatizou de modo emblemático, na modernidade, a questão da democracia visando fornecer uma solução plausível para a questão da deliberação política. Seu interesse por essa possibilidade e pelas implicações gerais para as boas formas de governo atesta 0 fato de que Hobbes não construíra suas ideias como fundamentalmente antidemocráticas, mas sim fornecendo, ao lado de uma nova teoria constitucional da monarquia, uma teoria plausível da democracia.

Na obra Elements of Law essa constatação fica visível, uma vez que nessa obra encontra-se a perspectiva de que a visão de Hobbes quanto ao governo democrático não é tão pessimista quanto ao Leviathan, e isso se deve, sobretudo, por ele considerar ser a democracia um elemento de transição, tanto para a aristocracia quanto para a monarquia. Assim, ao recolocar a democracia ao lado das outras formas de governo, Hobbes posiciona a questão da unidade como um elemento basilar na política. É partir dessa unidade que ele fornece os elementos indispensáveis ao seu projeto filosófico e político, ou seja, a ideia de povo e soberania.

Há, portanto, uma necessidade de suprimir uma vontade desconfigurada e desconexa para uma vontade única dirigida a um fim que converge as necessidades fundamentais para a obtenção da paz. Assim, tanto a paz quanto a segurança surgem em um ambiente de unidade de vontades.

Considera, portanto, a democracia como um elemento catalisador das vontades pelo qual a unidade representativa destas transforma a sua multiplicidade natural em uma unidade artificial e ordenada. Trata-se da constituição da vontade pública, isto é, aquela vontade do povo baseada na determinação de uma união de vontade capaz de subsumir a vontade de todos pela do soberano. Nesse caso, fica evidente que a vontade pública se associa a uma redução de vontades particulares dirigidas para um fim comum.

Por isso, Hobbes insiste que a democracia seja uma espécie de governo em que o soberano-representante é o próprio povo reunido em assembleia de todos, no qual cada homem particular é considerado um súdito. Nesses termos, a instauração da democracia é a condição para a preservação da unidade enquanto povo, uma vez que através dessa forma de governo se institui uma vontade única e soberana. 


\section{Notas}

${ }^{1}$ Professor adjunto de Filosofia na Universidade Federal do Maranhão. Bolsista de produtividade e Pesquisador na FAPEMA. Membro do GT Hobbes da ANPOF.

2 Na perspectiva de Hobbes, a monarquia é a forma mais adequada de exercer um governo, assim como é menos dispendiosa aos cofres públicos. Assim, devido aos interesses do soberano serem mais pessoais do que coletivos, ele utiliza o tempo de sua estada no poder para beneficiar a si e aos seus familiares em detrimento dos Estados. Na aristocracia e na soberania acontece algo semelhante, ou seja, o soberano beneficia seus familiares deixando os súditos em segundo plano.

${ }^{3}$ Hobbes menciona no Elements of Law que a noção de povo tem uma significação dupla: "Em um sentido, significa apenas o conjunto diferenciado de homens em função do lugar que habitam, como o povo da Inglaterra, ou o povo da França; o que nada mais é do que a multidão de pessoas particulares que habitam essas regiões, sem ter em consideração nenhum contrato ou pacto entre elas, pelos quais cada uma delas está obrigado às demais. Em outro sentido, povo significa pessoal civil, quer dizer, um homem ou um conselho em cuja vontade está incluída e contida na vontade de cada um em particular" $(2010,121)$.

4 Em Elements of Law, Hobbes relaciona o corpo político à ideia de união: "(...) quando a multidão está unida em um corpo político, constituindo assim um povo, em outro sentido do termo, e as vontades dos seus membros voluntariamente compreendida no soberano (...)" $(2010,122)$.

5 "A democracia engendra a instituição de um monarca da mesma maneira que ela engendrou a instituição da aristocracia, qual seja, pela decisão do povo soberano de transferir soberania a um homem nomeado e aprovado, pela pluralidade do sufrágio" (HOBBES, 2010, 119).

${ }^{6} \mathrm{Em}$ Elements of Law, Hobbes define a deliberação da seguinte forma: "(...) E deste medo pode suceder um novo apetite, e deste apetite outro medo alternadamente, até que a ação seja realizada, ou até que algum acidente se interponha de modo a impossibilitá-la. E assim cessará essa alternação entre o apetite e o medo. Essa sucessão alternada entre o apetite e o medo durante todo tempo em que temos em nosso poder a ação para fazê-la ou não a fazer é o que chamamos de deliberação" $(2010,83)$.

7 "Na deliberação, o último apetite, como também o último medo, é chamado vontade, a saber: o último apetite é a vontade de fazer ou não fazer" (HOBBES, 2010, 84).

8 De acordo com Zarka: "Sabe-se que a doutrina que a da formação da vontade política em Hobbes está centrada em torno da problemática da passagem do múltiplo ao uno. De que modo a multidão de indivíduos pode se tornar uma pessoa civil única? Como uma multiplicidade de vontades disparadas pode se transformar numa vontade política única? Estas duas questões dependem uma da outra: a resposta à primeira depende da resposta à segunda. Para saber como o Estado ou 
a cidade pode ser constituída como pessoa única, é necessário explicar a constituição de uma vontade política única" $(2001,72)$.

9 O significado de "multidão" deriva do latim multitudo. É também a variação de multus, que significa "muitos".

10 "Tendo que considerar aqui uma multidão de homens prestes a se unir por meio do pacto em um corpo político, para se defender uns dos outros e também contra os inimigos comuns $(\ldots)$ " $(2010,106)$.

11 "Em primeiro lugar, no que se refere aos indivíduos, eles são muitos, embora não constituam ainda uma só pessoa, e não se pode atribuir uma ação, feita em uma multidão de pessoas reunidas (...)" (HOBBES, 2021, 106).

12 Portanto, segundo Tuck, "a virtude política somente é possível no âmbito da unidade política" $(2006,23)$.

13 "Superficially, this sounds strikingly like Hobbes, but the key difference is that Segovia presumed that the multitudo had a separate collective existence from the presidents, and that it could exercise authority over itself whenever it gathered itself in one place" (TUCK, 2006, 118).

${ }^{14}$ Segundo Bobbio: "A luta do Estado moderno é uma longa luta pela unidade do poder. Esta unidade é o resultado de um processo simultâneo de libertação e de unificação: de libertação em face de uma autoridade tendencialmente universal, que, por ser de ordem espiritual, proclamava-se superior a todo poder civil; e de unificação em face das instituições menores, associações, corporações, cidades, que constituíam, na sociedade medieval, um perigo permanente de anarquia. Em consequência desses dois processos, a formação do Estado moderno coincide com o reconhecimento e com a consolidação da supremacia absoluta do poder político sobre qualquer outro poder humano. Esta supremacia absoluta se chama soberania" (1991, 65). 


\section{Referências}

BOBBIO, N. Thomas Hobbes. Tradução: Carlos Nélson Coutinho, Rio de Janeiro: Campus, 1991.

COPP, D. Hobbes on Artificial Persons and Collective Actions Author(s): Source: The Philosophical Review, Vol. 89, No. 4, 1980, p. 579606.

HOEKSTRA, K. A lion in the house: Hobbes and democracy. In: BRETT; TULLY (ed.). Rethinking the foundations of modern political thought. Cambridge: Cambridge University Press, 2006.

JAUME, L. Peuple et individu dans le debat Hobbes-Rousseau: d'une 'representation qui n'est pas celle du peuple, 'a un peuple qui n'est pas representable. In: La Representation, F. d'Arcy, Paris, ed. Economica, 1985, p. 39-53.

JAKONEN, M. Multitude in motion: Re-Readings on the Political Philosophy of Thomas Hobbes. Jyväskylä: University of Jyväskylä, 2013.

LEIVAS, C. A visão de Leviatã representação, afecção e vontade na filosofia natural e política de Hobbes. Porto Alegre: Class, 2019.

MATTOS, D. Pactos, palavras e ações em Thomas Hobbes. Belo Horizonte: Editora Dialética. 2020.

SMITH, S. 'Democracy and the Body Politic from Aristotle to Hobbes'. Political Theory 46, no. 2, 2018, p. 167-96.

HOBBES, T. Os elementos da lei natural e política (The elements os law). Tradução: Bruno Simões. São Paulo: Editora WMF Martins Fonte, 2010.

RODILLA, M. A. Hobbes: Soberanía y Bien del Pueblo. In: PERALES, Bonete. (org.) La Política desde la Ética. I. Historia de un Dilema. Barcelona: Proyecto A, 1998.

SOUKI, Nádia. Behemoth contra leviatã: Guerra civil na filosofia de Thomas Hobbes. Edições Loyola: São Paulo, 2008.

STRAUSS, L. A filosofia política de Hobbes: suas bases e sua gênese. São Paulo: É realizações, 2016. 
TUCK, R. Hobbes and democracy. In: BRETT; TULLY (ed.). Rethinking the foundations of modern political thought. Cambridge: Cambridge University Press, 2006.

VAN DUN, F. Hobbesian democracy. The Journal for the New Europe 2, 2005, p. 5-33.

ZARKA, Y. Hobbes e a invenção da vontade política pública. Discurso, n. 32, p. $71-84,2001$.

Received/Recebido: 22/10/21 Approved/Aprovado: 28/10/21 